\title{
Serum and dietary $\beta$-carotene and $\alpha$-tocopherol and incidence of type 2 diabetes mellitus in a community-based study of Swedish men: report from the Uppsala Longitudinal Study of Adult Men (ULSAM) study
}

\author{
J. Ärnlöv • B. Zethelius • U. Risérus • S. Basu • \\ C. Berne $\cdot$ B. Vessby $\cdot$ G. Alfthan $\cdot$ J. Helmersson
}

Received: 4 July 2008 / Accepted: 1 October 2008 / Published online: 5 November 2008

(C) Springer-Verlag 2008

\author{
Abstract \\ Aims/hypothesis To investigate the association of serum con- \\ centrations and dietary intake of $\beta$-carotene and $\alpha$-tocopherol \\ with type 2 diabetes incidence. \\ Methods Serum $\beta$-carotene, $\alpha$-tocopherol, lifestyle factors \\ (BMI, physical activity and smoking) and metabolic factors

\section{J. Ärnlöv $(\bowtie) \cdot$ B. Zethelius} \\ Department of Public Health and Caring Sciences/Geriatrics, \\ Uppsala University, \\ Uppsala Science Park, \\ SE-751 85 Uppsala, Sweden \\ e-mail: johan.arnlov@pubcare.uu.se

\section{J. Ärnlöv} \\ Department of Health and Social Sciences, Högskolan Dalarna, \\ Falun, Sweden \\ U. Risérus $\cdot \mathrm{S}$. Basu $\cdot$ B. Vessby $\cdot J$. Helmersson \\ Department of Public Health and Caring Sciences/Clinical \\ Nutrition and Metabolism, Uppsala University, \\ Uppsala, Sweden

\section{Berne} \\ Endocrinology, Diabetes and Metabolism, \\ Department of Medical Sciences, Uppsala University, \\ Uppsala, Sweden

\section{G. Alfthan} \\ Biomarker Laboratory, Department of Health and Functional \\ Capacity, National Public Health Institute (KTL), \\ Helsinki, Finland

\section{J. Helmersson} \\ Centre for Research and Development, \\ Uppsala University/County Council of Gävleborg, \\ Gävle, Sweden
}

(insulin sensitivity [homeostasis model assessment], acute insulin response and impaired fasting glucose) were analysed in 846 50-year-old non-diabetic Swedish men (participants in the Uppsala Longitudinal Study of Adult Men). Diabetes was identified in 245 participants at reinvestigations after 10, 20 and 27 years. At the 20 year reinvestigation, dietary intake of $\beta$-carotene and $\alpha$-tocopherol, insulin sensitivity (euglycaemic-hyperinsulinaemic clamp) and insulin secretion (early insulin response in OGTT) were determined.

Results The highest tertile of serum $\beta$-carotene at age 50 $(>0.335 \mu \mathrm{mol} / \mathrm{l})$ was associated with $59 \%$ lower risk of diabetes during follow-up compared with the lowest tertile $(<0.210 \mu \mathrm{mol} / \mathrm{l})$ after adjustment for lifestyle and metabolic factors $(p<0.01)$. The highest tertile of lipid-corrected serum $\alpha$-tocopherol at age $50(>3.67 \mu \mathrm{mol} / \mathrm{mmol})$ was associated with $46 \%$ lower risk of diabetes compared with the lowest tertile $(<3.25 \mu \mathrm{mol} / \mathrm{mmol})$ independently of metabolic factors $(p<0.05)$. Moreover, lower serum $\beta$-carotene and $\alpha$-tocopherol concentrations were independently associated with impaired insulin sensitivity $(p<0.001)$, but not with early insulin response, in a subsample of non-diabetic individuals 20 years later. Dietary intake of $\beta$-carotene and $\alpha$-tocopherol independently predicted type 2 diabetes during 7 years of follow-up.

Conclusions/interpretation Serum concentrations and dietary intakes of $\beta$-carotene and $\alpha$-tocopherol independently predicted insulin resistance and type 2 diabetes incidence during 27 years of follow-up in a community-based study of men. This result supports the importance of impaired antioxidant status for the development of insulin resistance and type 2 diabetes. 
Keywords Antioxidants $\cdot \beta$-Carotene $\cdot$ Diabetes $\cdot$ Human . Insulin resistance $\cdot \alpha$-Tocopherol

Abbreviations
HOMA $\quad$ Homeostasis model assessment
ULSAM $\quad$ Uppsala Longitudinal Study of Adult Men

\section{Introduction}

Type 2 diabetes mellitus is increasing rapidly worldwide. Recent evidence suggests that, apart from obesity and physical inactivity, oxidative stress and inflammation may also be important in the development of insulin resistance and type 2 diabetes [1-5]. Oxidative stress indicates an imbalance between the production of reactive oxygen species (free radicals) and the antioxidant defence system [6]. Oxidative stress is evident in established type 2 diabetes, possibly because of insufficient antioxidant defence, and oxidative stress has been suggested to precede and accelerate the development of type 2 diabetes [1].

Several reports have suggested that low serum concentrations or low dietary intake of antioxidants such as $\beta$-carotene and $\alpha$-tocopherol play independent roles in the pathogenesis of type 2 diabetes [7-13] while other investigators report no independent association with these antioxidants and the development of type 2 diabetes [1416]. One reason for the inconsistencies in previous observational studies may be that some prior investigations were limited by a cross-sectional design $[10,11,16]$, short followup $[7,9,12]$, a small study sample $[10,15]$, a low number of incident type 2 diabetes cases during follow-up [9, 15], limited adjustment for important lifestyle factors (such as level of physical activity) $[8,9,15]$ or metabolic factors $[8,9,12-15]$ at baseline, and limitations in the classification of diabetic and non-diabetic individuals during follow-up $[8,14,15]$. Furthermore, data are scarce on the longitudinal association of $\beta$-carotene and $\alpha$-tocopherol with insulin sensitivity and insulin secretion. Interestingly, previous supplementation trials with $\beta$-carotene or $\alpha$-tocopherol do not support the notion of a causal role for these antioxidants in the prevention of diabetes [12, 14, 17, 18].

In the present study, we investigated the association between serum concentrations and dietary intake of $\beta$-carotene and $\alpha$-tocopherol with the incidence of type 2 diabetes in a large community-based sample of Swedish men followed for up to 27 years and whether this relation was independent of lifestyle factors and measurements of glucose and insulin metabolism. Furthermore, we investigated the longitudinal association between these antioxidants and the two main underlying causes of type 2 diabetes insulin resistance (estimated by euglycaemichyperinsulinaemic clamp) and impaired insulin secretion in a subsample free from type 2 diabetes.

\section{Methods}

Study population and design

Between 1970 and 1973 all men born between 1920 and 1924 and living in Uppsala, Sweden, were invited to take part in a health survey with the aim of identifying risk factors for cardiovascular disease and type 2 diabetes in middle-aged men (Uppsala Longitudinal Study of Adult Men, ULSAM). Of the men invited, $82 \%$ (2,322 men) participated in the investigation. The cohort was reinvestigated after 10, 20 and 27 years when the participants were 60, 70 and 77 years old, respectively (see Fig. 1 for overview of the study design). In addition to the reinvestigations, all participants were followed with annual updates on morbidity using the Swedish hospital discharge register. The ULSAM study is described in detail at www. pubcare.uu.se/ULSAM.

Serum concentrations of $\beta$-carotene and $\alpha$-tocopherol were analysed at the baseline investigation at age 50 years.
Fig. 1 Overview of the study design of the ULSAM cohort and analyses performed in the present study. ${ }^{a}$ Analysed in participants without type 2 diabetes

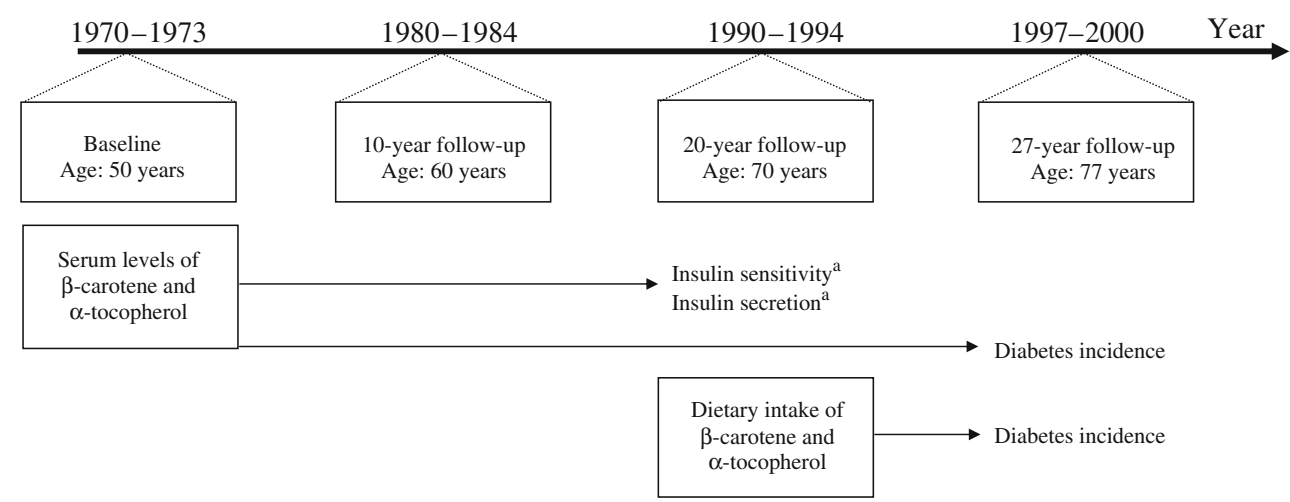


Data on the dietary intake of $\beta$-carotene and $\alpha$-tocopherol were available at the 20 year follow-up when the participants were 70 years old (Fig. 1). The prevalence of type 2 diabetes was assessed at all investigations according to the WHO criteria from 1999 using fasting concentrations of glucose (fasting blood glucose $\geq 6.1 \mathrm{mmol} / 1$ [baseline and 10 year investigations] or fasting plasma glucose $\geq 7.0$ [20 year and 27 year reinvestigations] or the use of glucose-lowering medication). In addition, participants with type 2 diabetes were also identified using data from the Swedish national hospital discharge register (ICD-9 code 250 or ICD-10 E10-E14; http://www.who. int/classifications/icd/en/).

Examinations and biochemical analyses

Baseline at age 50 years Serum $\beta$-carotene and $\alpha$-tocopherol determinations were available in 1,934 participants free from type 2 diabetes at age 50 years. Of these, 708 men had fasting glucose determinations available at the 27 year follow-up examination. In addition, 138 diabetic men were identified at the follow-up investigations or via the hospital discharge registry. Thus, 846 men constituted the study population from age 50 with 27 years of followup. See Fig. 1 for an overview of the follow-up data.

Examinations performed at age 50 years included a medical questionnaire, blood sampling (after an overnight fast) with fasting and post-load glucose and insulin levels using an IVGTT, lipid and electrolyte determinations and anthropometric measurements, as described previously [19].

Insulin sensitivity was calculated from plasma glucose and insulin concentrations using homeostasis model assessment (HOMA).[20] The acute insulin response was defined as the mean value of the serum insulin concentrations determined at 4 and 6 min of the IVGTT. Impaired fasting glucose was defined as a fasting blood glucose concentration of 5.0-6.0 mmol/l. $\alpha$-Tocopherol and $\beta$-carotene were determined simultaneously by HPLC in serum samples that had been stored in liquid nitrogen for about 15 years [21]. The serum tocopherol concentrations reported are corrected for the sum of serum cholesterol and serum triacylglycerol (tocopherol/[cholesterol + triacylglycerol]) [22].

Leisure time physical activity was estimated using a questionnaire containing four physical activity categories: sedentary, moderate, regular and athletic [19]. Smoking status was assessed from interview reports.

Baseline at age 70 years Dietary records were available for 1,021 non-diabetic participants at the 20 year reinvestigation at age 70 years. Of these, 678 had available fasting glucose determinations after 7 years (at the 27 year followup examination). In addition, six diabetic men were identified via the hospital discharge registry. Thus, 684 men constituted the study population from age 70 years (Fig. 1, Table 1).

The insulin sensitivity index was determined by euglycaemic-hyperinsulinaemic clamp [23]. Insulin secretion was measured as the early insulin response during an OGTT (30 min increment of insulin/30 min increment of glucose) [24]. Impaired fasting glucose was defined as fasting plasma glucose concentration of 5.6-6.9 mmol/l.

A dietitian instructed all participants to record their dietary intake using a 7-day pre-coded food diary. Daily intakes of the antioxidants were calculated using a computerised program (MATs; Rudans Lättdata, Västerås, Sweden) and the Swedish National Food Administration database.

\section{Statistical analyses}

Transformation was performed to achieve normal distribution if necessary. Two-tailed $95 \% \mathrm{CI}$ and $p$ values are given, $p \leq 0.05$ being regarded as significant. We analysed the concentrations of antioxidants both as continuous variables (expressed as $1-\mathrm{SD}$ ) and as tertiles in order to

Table 1 Baseline characteristics

\begin{tabular}{|c|c|c|}
\hline Characteristic & $\begin{array}{l}\text { Baseline at } \\
\text { age } 50 \text { years }\end{array}$ & $\begin{array}{l}\text { Baseline at } \\
\text { age } 70 \text { years }\end{array}$ \\
\hline Number of participants & 846 & 684 \\
\hline \multicolumn{3}{|l|}{ Antioxidants } \\
\hline Serum $\beta$-carotene $(\mu \mathrm{mol} / \mathrm{l})$ & $0.313 \pm 0.196$ & - \\
\hline $\begin{array}{l}\text { Serum } \alpha \text {-tocopherol }(\mu \mathrm{mol} / \mathrm{mmol} \text {, } \\
\text { lipid-corrected) }\end{array}$ & $3.51 \pm 0.63$ & - \\
\hline Dietary $\beta$-carotene (mg/day) & - & $1.7 \pm 1.4$ \\
\hline Dietary $\alpha$-tocopherol (mg/day) & - & $5.7 \pm 2.3$ \\
\hline \multicolumn{3}{|l|}{ Lifestyle factors } \\
\hline BMI $\left(\mathrm{kg} / \mathrm{m}^{2}\right)$ & $25.2 \pm 3.2$ & $26.0 \pm 3.2$ \\
\hline \multicolumn{3}{|l|}{ Physical activity level (\%) } \\
\hline Sedentary & 14 & 3 \\
\hline Moderate & 35 & 31 \\
\hline Regular & 46 & 59 \\
\hline Athletic & 6 & 7 \\
\hline Smoking prevalence & 45 & 16 \\
\hline \multicolumn{3}{|l|}{ Metabolic factors } \\
\hline Fasting blood glucose (mmol/l) & $4.9 \pm 0.49$ & - \\
\hline Fasting plasma glucose $(\mathrm{mmol} / \mathrm{l})$ & - & $5.4 \pm 0.6$ \\
\hline Fasting insulin (pmol/l) & $90.3 \pm 53.5$ & $84.7 \pm 46.5$ \\
\hline HOMA insulin sensitivity & $2.9 \pm 1.8$ & - \\
\hline $\begin{array}{l}\text { Clamp insulin sensitivity index } \\
\left(\mathrm{mg} \mathrm{kg}^{-1} \mathrm{~min}^{-1}[\mathrm{pmol} / 1]^{-1} \times 100\right)\end{array}$ & - & $0.8 \pm 0.3$ \\
\hline Acute insulin response (pmol/l) & $481 \pm 344$ & - \\
\hline Early insulin response (pmol/mmol) & - & $14.6 \pm 11.5$ \\
\hline Impaired fasting glucose $(\%)$ & 38 & 31 \\
\hline
\end{tabular}

Data are mean \pm SD for continuous variables and prevalence (\%) for categorical variables 
assess non-linear relationships. Logistic regression models were used to assess relationships.

We used four sets of models: (A) unadjusted analyses; (B) lifestyle model (multivariate analyses using BMI, level of physical activity and smoking status as baseline covariates); (C) metabolic model (multivariate analyses; the baseline covariates for the baseline at age 50 years were impaired fasting glucose, insulin sensitivity [HOMA] and acute insulin response at IVGTT; for the baseline at age 70 years they were impaired fasting glucose, insulin sensitivity [clamp] and early insulin response in the OGTT); (D) combined model (lifestyle model + metabolic model).

We also investigated the relationships between the serum concentrations of antioxidants at age 50 years and insulin sensitivity and insulin secretion in non-diabetic individuals at age 70 using linear regression models $(n=848)$. In secondary analyses, we also adjusted our analyses for socioeconomic status or dietary intake of fibres and alcohol. In order to limit the risk of a healthy cohort effect, we also performed exploratory analyses of the relation between serum concentrations of the antioxidants at age 50 years and type 2 diabetes incidence at each of the follow-ups after 10, 20 and 27 years (Fig. 2). In these analyses only those who attended a specific re-examination were included. STATA 10.0 (Stata, College Station, TX, USA) was used to perform the analyses.

\section{Results}

Baseline characteristics are shown in Table 1. During follow-up 245 participants developed type 2 diabetes. The number of events and the numbers at risk in the tertiles of serum and dietary $\beta$-carotene and $\alpha$-tocopherol concentrations are shown in Table 2.

Serum concentrations of $\beta$-carotene and $\alpha$-tocopherol at age 50 years and incidence of type 2 diabetes during 27 years of follow-up

In crude and multivariable models adjusting for lifestyle factors (BMI, physical activity and smoking) and metabolic factors (fasting hyperglycaemia, HOMA insulin sensitivity index and acute insulin response), an increase of $1 \mathrm{SD}$ in serum $\beta$-carotene at age 50 years was associated with 25 $42 \%$ lower risk of type 2 diabetes incidence during followup and the highest tertile of serum $\beta$-carotene at age 50 was associated with $49-69 \%$ lower risk of type 2 diabetes compared with the lowest tertile (models $\mathrm{A}-\mathrm{D} ; p<0.002$; Table 2). In secondary analyses, an increase of $1 \mathrm{SD}$ in serum $\beta$-carotene at age 50 was associated with a lower incidence of type 2 diabetes at the follow-up after 10, 20 and 27 years in both crude and multivariable models (Fig. 2).
Follow-up

(no. of events/no. at risk)

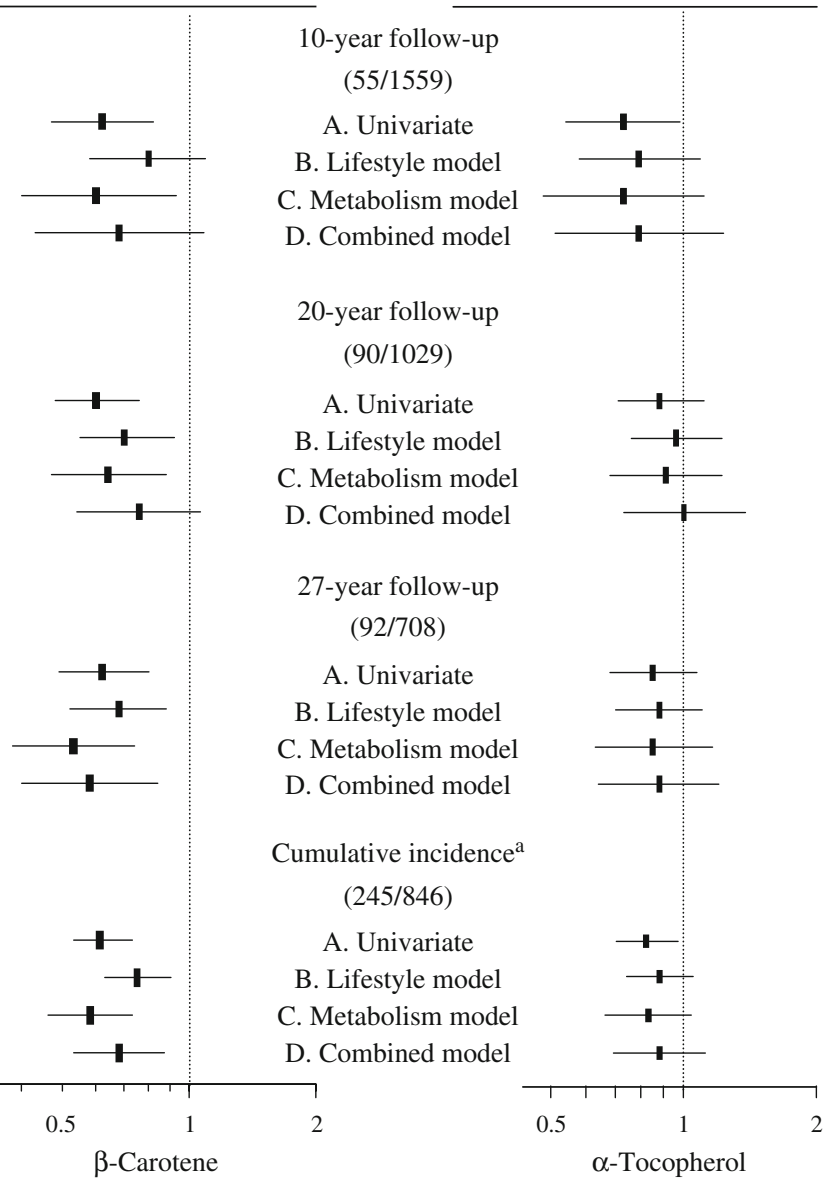

Fig. 2 Univariate and multivariate odds ratios for an increase of $1 \mathrm{SD}$ in serum concentrations of $\beta$-carotene and $\alpha$-tocopherol for type 2 diabetes incidence at the different re-examinations during follow-up. ${ }^{a}$ Cumulative incidence: participants with type 2 diabetes at the investigation after 10,20 or 27 years or a diagnosis of type 2 diabetes from the hospital discharge registry compared with participants without type 2 diabetes at the investigation after 27 years. Cumulative incidence data are presented in greater detail in Table 2. Lifestyle model = BMI, level of physical activity and smoking at baseline; metabolic model = HOMA insulin sensitivity index, acute insulin response and impaired fasting glucose; combined model $=$ lifestyle model + metabolic model

An increase of $1 \mathrm{SD}$ in serum $\alpha$-tocopherol at age 50 years was associated with $50 \%$ lower risk of type 2 diabetes incidence in the crude model (A). Furthermore, men in the highest tertile of serum $\alpha$-tocopherol at age 50 had $41-46 \%$ lower risk of type 2 diabetes compared with the lowest tertile in both crude and multivariable models adjusted for metabolic factors (models A and C; see Table 2 for details). In secondary analyses, the association between serum $\beta$-carotene, $\alpha$-tocopherol and diabetes incidence remained essentially unaltered after adjustment for socioeconomic status (data not shown) 
Dietary intake of $\beta$-carotene and $\alpha$-tocopherol at age 70 years and incidence of type 2 diabetes during 7 years of follow-up

During follow-up, 57 participants developed type 2 diabetes. In both crude and multivariable models adjusting for lifestyle factors and metabolic factors, an increase of $1 \mathrm{SD}$ in dietary intake of $\beta$-carotene at age 70 was associated with $29-34 \%$ lower risk of type 2 diabetes incidence during follow-up in all models (models A-D; Table 2). Furthermore, men in the highest tertile of dietary intake of $\beta$-carotene at age 70 had $49-50 \%$ lower risk of type 2 diabetes compared with the lowest tertile in both crude and multivariable models adjusted for lifestyle factors (models A and B; Table 2).

In both crude and multivariable models adjusting for lifestyle factors and metabolic factors, an increase of $1 \mathrm{SD}$ in dietary intake of $\alpha$-tocopherol at age 70 was associated with $27-35 \%$ lower risk of type 2 diabetes incidence (models A-C; $p<0.05$; Table 2). Furthermore, the men in the highest tertile of dietary intake of $\alpha$-tocopherol at age 70 had $49 \%$ lower risk of type 2 diabetes compared with the lowest tertile in the crude model (model A; Table 2). In secondary analyses, the association between dietary intake of $\beta$-carotene and $\alpha$-tocopherol and diabetes incidence remained essentially the same after adjustment for socioeconomic status or dietary intake of fibre and alcohol (data not shown).

Serum concentrations of $\beta$-carotene and $\alpha$-tocopherol at age 50 years and insulin sensitivity and early insulin response at age 70 years in non-diabetic participants

In a linear regression model, an increase of $1 \mathrm{SD}$ in serum $\beta$-carotene at age 50 years was associated with 0.08 units

Table 2 Crude and multivariable associations between $\beta$-carotene, $\alpha$-tocopherol and type 2 diabetes incidence during follow-up

\begin{tabular}{|c|c|c|c|c|}
\hline \multirow[t]{2}{*}{ Variable } & \multicolumn{3}{|l|}{ Tertile } & \multirow{2}{*}{$\begin{array}{l}\text { Continuous } \\
1 \mathrm{SD} \text { increase }\end{array}$} \\
\hline & Low (referent) & Middle & High & \\
\hline \multicolumn{5}{|l|}{$\beta$-Carotene } \\
\hline \multicolumn{5}{|l|}{ Serum level at age 50 years } \\
\hline Number of events/number at risk & $116 / 284$ & $74 / 284$ & $55 / 278$ & \\
\hline A. Crude model & 1 & $0.51(0.35-0.72)^{\mathrm{c}}$ & $0.35(0.24-0.51)^{\mathrm{c}}$ & $0.62(0.53-0.73)^{\mathrm{c}}$ \\
\hline B. Lifestyle model & 1 & $0.65(0.49-0.95)^{\mathrm{a}}$ & $0.51(0.33-0.78)^{\mathrm{b}}$ & $0.75(0.62-0.89)^{\mathrm{c}}$ \\
\hline C. Metabolism model & 1 & $0.46(0.28-0.75)^{\mathrm{b}}$ & $0.31(0.18-0.53)^{\mathrm{c}}$ & $0.58(0.46-0.73)^{\mathrm{c}}$ \\
\hline D. Combined model & 1 & $0.54(0.32-0.92)^{\mathrm{a}}$ & $0.41(0.23-0.74)^{\mathrm{b}}$ & $0.68(0.53-0.89)^{\mathrm{b}}$ \\
\hline \multicolumn{5}{|l|}{ Dietary intake at age 70 years } \\
\hline Number of events/number at risk & $29 / 230$ & $13 / 228$ & $15 / 226$ & \\
\hline A. Crude model & 1 & $0.42(0.21-0.83)^{\mathrm{a}}$ & $0.49(0.26-0.95)^{\mathrm{a}}$ & $0.66(0.50-0.86)^{b}$ \\
\hline B. Lifestyle model & 1 & $0.49(0.24-0.98)^{\mathrm{a}}$ & $0.50(0.25-1.00)^{\mathrm{a}}$ & $0.70(0.51-0.95)^{\mathrm{a}}$ \\
\hline C. Metabolism model & 1 & $0.42(0.20-0.90)^{\mathrm{a}}$ & $0.67(0.32-1.40)$ & $0.69(0.52-0.91)^{\mathrm{b}}$ \\
\hline D. Combined model & 1 & $0.45(0.21-0.97)^{\mathrm{a}}$ & $0.67(0.31-1.44)$ & $0.71(0.52-0.98)^{\mathrm{a}}$ \\
\hline \multicolumn{5}{|l|}{$\alpha$-Tocopherol } \\
\hline \multicolumn{5}{|l|}{ Serum level at age 50 years } \\
\hline Number of events/number at risk & $99 / 282$ & $77 / 282$ & $69 / 282$ & \\
\hline A. Crude model & 1 & $0.68(0.48-0.98)^{\mathrm{a}}$ & $0.59(0.41-0.85)^{\mathrm{b}}$ & $0.50(0.28-0.91)^{\mathrm{a}}$ \\
\hline B. Lifestyle model & 1 & $0.76(0.51-1.13)$ & $0.70(0.46-1.04)^{\mathrm{d}}$ & $0.65(0.34-1.23)$ \\
\hline C. Metabolism model & 1 & $0.70(0.44-1.13)$ & $0.54(0.32-0.91)^{\mathrm{a}}$ & $0.51(0.22-1.19)$ \\
\hline D. Combined model & 1 & $0.76(0.45-1.28)$ & $0.61(0.34-1.07)^{\mathrm{d}}$ & $0.64(0.26-1.57)$ \\
\hline \multicolumn{5}{|l|}{ Dietary intake at age 70 years } \\
\hline Number of events/number at risk & $24 / 228$ & $20 / 228$ & $13 / 228$ & \\
\hline A. Crude model & 1 & $0.82(0.44-1.53)$ & $0.51(0.25-1.04)$ & $0.65(0.49-0.86)^{\mathrm{b}}$ \\
\hline B. Lifestyle model & 1 & $0.95(0.49-1.83)$ & $0.61(0.29-1.29)$ & $0.73(0.53-1.00)^{\mathrm{a}}$ \\
\hline C. Metabolism model & 1 & $0.88(0.43-1.82)$ & $0.61(0.28-1.31)$ & $0.72(0.54-0.97)^{\mathrm{a}}$ \\
\hline D. Combined model & 1 & $1.06(0.50-2.22)$ & $0.70(0.31-1.58)$ & $0.78(0.56-1.09)$ \\
\hline
\end{tabular}

Data are odds ratio $(95 \% \mathrm{CI})$

Ranges of serum $\beta$-carotene tertiles ( $\mu \mathrm{mol} / \mathrm{l})$ : low, $<0.210$; middle, $0.210-0.335$; high, $>0.335$

Ranges of dietary $\beta$-carotene tertiles (mg/day): low, $<1.02$; middle, 1.02-1.89; high, $>1.89$

Ranges of serum $\alpha$-tocopherol tertiles $(\mu \mathrm{mol} / \mathrm{mmol})$ : low, $<3.25$; middle, $3.25-3.67$; high, $>3.67$

Ranges of dietary $\alpha$-tocopherol tertiles (mg/day): low tertile, $<4.82$; middle, $4.82-6.30 ;$ high, $>6.30$

${ }^{\mathrm{a}} p<0.05,{ }^{\mathrm{b}} p<0.01,{ }^{\mathrm{c}} p<0.001,{ }^{\mathrm{d}} p=0.08$ 
higher insulin sensitivity in non-diabetic participants at age 70 years $(95 \%$ CI $0.06-0.11, p<0.001)$. The results remained essentially the same in the multivariable linear regression models adjusting for both lifestyle factors and metabolic factors (models B-D; regression coefficient $0.05-0.0 .06, p<0.001)$.

Moreover, an increase of $1 \mathrm{SD}$ in serum $\alpha$-tocopherol at age 50 years was associated with 0.04 units higher insulin sensitivity in non-diabetic participants at age 70 years $(95 \%$ CI $0.01-0.06, p<0.01)$. The results remained essentially the same in the multivariable linear regression models adjusting for both lifestyle factors and metabolic factors (models $\mathrm{B}-\mathrm{D}$; regression coefficient $0.03, p<0.05$ ).

There was no relation between serum $\beta$-carotene or $\alpha$-tocopherol at age 50 years and insulin secretion (early insulin response) at age 70 years in any model ( $p>0.07$ for all).

\section{Discussion}

\section{Principal findings}

In this study, serum levels and dietary intake of $\beta$-carotene and $\alpha$-tocopherol were shown to predict the incidence of type 2 diabetes in crude analyses. However, after adjustment for both lifestyle factors and metabolic factors, only serum and dietary $\beta$-carotene remained significantly associated with the development of diabetes. Our data suggest that the proposed glucose-lowering effect of the antioxidants could be mediated by improved insulin sensitivity as both $\beta$-carotene and $\alpha$-tocopherol independently predicted insulin sensitivity after 20 years of follow-up in a subsample free from diabetes. No longitudinal relations were found between $\beta$-carotene and $\alpha$-tocopherol and insulin secretion after 20 years.

\section{Comparisons with the literature}

The present longitudinal association of either serum concentration or dietary intake of $\beta$-carotene and the incidence of type 2 diabetes is in accordance with some [11-13] but not all [8, 14, 15] previous reports. As previously noted, these discrepancies could have arisen because these studies differed in study design, sample size, adjustment for potential confounders and how type 2 diabetes cases were identified during follow-up. Strengths of the present study include the long-term follow-up, the large study sample with many participants identified with type 2 diabetes during follow-up, the detailed characterisation of lifestyle and metabolic factors in several investigation cycles, and the fact that we studied both serum concentrations and dietary intake of the antioxidants. Furthermore, we are aware of no previous studies that have reported that $\beta$-carotene concentration predicts type 2 diabetes independently of metabolic factors such as baseline insulin sensitivity, insulin secretion and impaired fasting glucose.

Our findings that both serum levels and dietary intake of $\alpha$-tocopherol predict the incidence of diabetes in crude analyses are in accordance with prior longitudinal evidence from observational studies supporting a role for $\alpha$-tocopherol in the development of diabetes [7-9]. However, in contrast to previous studies [7-9], our data do not support the notion of a major independent impact of circulating levels of $\alpha$-tocopherol on the risk of diabetes.

The independent longitudinal association between $\beta$-carotene and $\alpha$-tocopherol and insulin sensitivity (as measured by the gold standard euglycaemic-hyperinsulinaemic clamp technique) seen in the present study is new and suggests that the proposed glucose-lowering effect of these antioxidants is mediated by improved insulin sensitivity rather than improved insulin secretion. In the light of this, the interpretation of models in which metabolic factors at baseline were taken into account could be problematic, as this could constitute an over-adjustment, i.e. the metabolic factors could be considered to be in the causal pathway between low antioxidant levels and the development of diabetes. The fact that the antioxidants consistently predicted diabetes independently of the metabolic factors argues against over-adjustment as an explanation of our findings. There are, however, a few other potential explanations for the fact that the associations were independent of metabolic factors. Even though the association between the antioxidants and the development of diabetes is mediated by insulin resistance, it is reasonable to assume that there may be residual confounding involved as a single measurement of metabolic status at baseline is probably a poor reflector of metabolic status during the 27 year follow-up. Moreover, it is possible that the antioxidants are involved early in the pathological processes leading to diabetes and that it takes a long period of exposure to low antioxidant levels before metabolic factors are affected. Importantly, as this was an observational study, no firm conclusions on causality can be drawn.

Possible mechanisms for the observed associations

The idea of a causal role of the balance between oxidative stress and antioxidant defence in the development of diabetes is supported by numerous experimental and clinical studies. Several cross-sectional studies have reported that isoprostanes (gold standard indicators of oxidative stress) are elevated in patients with type 2 diabetes $[5,25,26]$. Damage by free radicals is possibly involved in both impaired insulin sensitivity [27] and beta cell destruction leading to impaired insulin secretion, the 
two major underlying causes of type 2 diabetes [1]. In experimental studies, antioxidants have been shown to improve insulin sensitivity [28] and other experimental data suggest that free radicals impair intracellular glucose transport [29]. $\beta$-Carotene has been shown to be a potent free radical scavenger and $\alpha$-tocopherol is a chain-breaking antioxidant, and adequate concentrations of these antioxidants would possibly reduce the level of oxidative stress $[26,30,31]$. Thus, the protective effect of these antioxidants seen in the present study could be related to their ability to reduce oxidative stress. Furthermore, low-grade inflammation predicts type 2 diabetes [32], and it is possible that antioxidants exert an glucose-lowering effect through inhibition of inflammation, since markers of oxidative stress and inflammation have been shown to be closely linked [27]. There are also in vitro data suggesting that certain antioxidants exert insulin-like effects [33].

Apart from $\beta$-carotene and $\alpha$-tocopherol, several other types of antioxidants, such as other carotenoids [8], magnesium [34] and flavonoids [35], and polyphenols [36] seem to protect against the development of type 2 diabetes. Foods rich in antioxidants, such as fruits, vegetable, coffee, tea and wine, often contain several hundred antioxidants and the dietary intake of different antioxidantrich foods has been shown to be more closely associated with increased plasma concentrations of $\beta$-carotene than plasma $\alpha$-tocopherol $[37,38]$. This may provide an explanation why $\beta$-carotene was more closely associated with the development of type 2 diabetes than $\alpha$-tocopherol; $\beta$-carotene could be a better marker for total dietary antioxidant intake [38]. This is supported by the fact that dietary intake of $\beta$-carotene and $\alpha$-tocopherol contributes only a fraction of the total intake of antioxidants [37, 38].

\section{Clinical implications}

Even though several epidemiological studies support the notion of a causal role for $\beta$-carotene or $\alpha$-tocopherol in the development of type 2 diabetes, results from antioxidant supplementation trials do not. Data from several large supplementation trials with $\beta$-carotene or $\alpha$-tocopherol showed no benefit in the prevention of type 2 diabetes $[12,14,17,18]$. However, in the above supplementation trials, patients were included without evaluation of either their oxidative stress or antioxidant status, and such indiscriminate enrolment could perhaps account for the absence of a protective affect. Perhaps only those with low basal levels of antioxidants would benefit from such supplementation. Furthermore, the lack of effect of $\alpha$-tocopherol in preventing type 2 diabetes in the above supplementation studies may also be related to insufficient doses of $\alpha$-tocopherol given. A recent study showed that $\alpha$-tocopherol must be given in doses of 1 or $2 \mathrm{~g}$ /day for a period of at least 4 months to reduce oxidative stress (as measured by isoprostanes) [39]. The $\alpha$-tocopherol doses used in the prevention trials described above were several times lower than $1 \mathrm{~g} /$ day, which could be a factor contributing to the observed absence of protective effect in these studies. Moreover, the selection of different forms of antioxidants might be of importance as the natural forms of antioxidants in foods may have different biological activity or potency compared with the synthetic compounds used in supplements [40-42]. Another difference between synthetic antioxidant supplementation and dietary intake of antioxidants is that other naturally occurring antioxidants and micronutrients may accompany the intake of antioxidant-rich foods. As dietary intake of $\beta$-carotene and $\alpha$-tocopherol contributes only a small portion of the total intake of dietary antioxidants, it is possible that it is the combination of antioxidants found in antioxidant-rich foods that is protective rather than the separate effects of each antioxidant. There may also be other unknown factors in antioxidant-rich foods that mediate the beneficial effect.

\section{Study limitations}

Our study has several limitations. As we examined men at 50 and 70 years of age with the same ethnic background, the results may have limited generalisability to women and other age and ethnic groups. Moreover, the results of the study might also have been affected by a healthy cohort effect, i.e. by the dropout of the least healthy individuals during follow-up. We addressed this issue by performing separate analyses at each follow-up investigation (Fig. 2) and by including type 2 diabetes data from the hospital discharge registry for non-participants. Any potential bias due to a healthy cohort effect would probably make the associations weaker.

Both $\beta$-carotene and $\alpha$-tocopherol were analysed in samples that had been frozen for approximately 15 years. Thus, there is a risk that the analyses of frozen samples could have affected the absolute levels of the antioxidants compared with analyses of fresh samples. However, both $\beta$-carotene and $\alpha$-tocopherol have been shown to be stable in frozen samples over time [43] and any potential influence of the prolonged freezing would probably drive the association towards the null hypothesis.

The point estimates for serum $\alpha$-tocopherol for the development of type 2 diabetes were fairly similar throughout the follow-up (Fig. 2). At the end of the follow-up, with a larger number of type 2 diabetes cases, the confidence intervals became narrower, leaving $\alpha$-tocopherol borderline significant after adjustment for both lifestyle and metabolic factors (Table 2, Fig. 2). This may indicate that in a larger population these multivariable associations would have reached greater statistical significance. 


\section{Conclusion}

Our findings support the notion that impaired antioxidant status, as reflected by lower concentrations of circulating and dietary $\beta$-carotene and $\alpha$-tocopherol, independently predicts the development of insulin resistance and type 2 diabetes in middle-aged and elderly Swedish men. Whether $\beta$-carotene and $\alpha$-tocopherol contribute causally to a lower risk of type 2 diabetes, or whether low antioxidant concentrations merely reflect a diet with insufficient fruit and vegetable intake or an endogenous defective antioxidant defence remains to be determined.

Acknowledgements We thank E. Sejby, B. Simu and S. Tengblad for technical assistance. The study was supported by grants from the Swedish Research Council (2006-6555), Swedish Heart-Lung foundation, Gustaf Adolf Johanssons Minnesfond, Josef och Linnea Carlssons Minnesfond, Royal Scientific Society Foundation (Kungliga vetenskapssamhällets fond), Ernfors Fund for Diabetes Research, the Swedish Diabetes Association and Thuréus Foundation.

Duality of interest The authors declare that there is no duality of interest associated with this manuscript.

\section{References}

1. Ceriello A, Motz E (2004) Is oxidative stress the pathogenic mechanism underlying insulin resistance, diabetes, and cardiovascular disease? The common soil hypothesis revisited. Arterioscler Thromb Vasc Biol 24:816-823

2. Riserus U, Arner P, Brismar K, Vessby B (2002) Treatment with dietary trans 10 cis 12 conjugated linoleic acid causes isomerspecific insulin resistance in obese men with the metabolic syndrome. Diabetes Care 25:1516-1521

3. Riserus U, Vessby B, Arnlov J, Basu S (2004) Effects of cis-9, trans-11 conjugated linoleic acid supplementation on insulin sensitivity, lipid peroxidation, and proinflammatory markers in obese men. Am J Clin Nutr 80:279-283

4. Bruce CR, Carey AL, Hawley JA, Febbraio MA (2003) Intramuscular heat shock protein 72 and heme oxygenase-1 mRNA are reduced in patients with type 2 diabetes: evidence that insulin resistance is associated with a disturbed antioxidant defense mechanism. Diabetes 52:2338-2345

5. Helmersson J, Vessby B, Larsson A, Basu S (2004) Association of type 2 diabetes with cyclooxygenase-mediated inflammation and oxidative stress in an elderly population. Circulation 109:1729 1734

6. Betteridge DJ (2000) What is oxidative stress? Metabolism 49:38

7. Mayer-Davis EJ, Costacou T, King I, Zaccaro DJ, Bell RA (2002) Plasma and dietary vitamin $\mathrm{E}$ in relation to incidence of type 2 diabetes: The Insulin Resistance and Atherosclerosis Study (IRAS). Diabetes Care 25:2172-2177

8. Montonen J, Knekt P, Jarvinen R, Reunanen A (2004) Dietary antioxidant intake and risk of type 2 diabetes. Diabetes Care 27:362-366

9. Salonen JT, Nyyssonen K, Tuomainen TP et al (1995) Increased risk of non-insulin dependent diabetes mellitus at low plasma vitamin E concentrations: a four year follow up study in men. BMJ 311:1124-1127
10. Ylonen K, Alfthan G, Groop L, Saloranta C, Aro A, Virtanen SM (2003) Dietary intakes and plasma concentrations of carotenoids and tocopherols in relation to glucose metabolism in subjects at high risk of type 2 diabetes: the Botnia Dietary Study. Am J Clin Nutr 77:1434-1441

11. Coyne T, Ibiebele TI, Baade PD et al (2005) Diabetes mellitus and serum carotenoids: findings of a population-based study in Queensland, Australia. Am J Clin Nutr 82:685-693

12. Czernichow S, Couthouis A, Bertrais S et al (2006) Antioxidant supplementation does not affect fasting plasma glucose in the Supplementation with Antioxidant Vitamins and Minerals (SU.VI. MAX) study in France: association with dietary intake and plasma concentrations. Am J Clin Nutr 84:395-399

13. Hozawa A, Jacobs DR Jr., Steffes MW, Gross MD, Steffen LM, Lee DH (2006) Associations of serum carotenoid concentrations with the development of diabetes and with insulin concentration: interaction with smoking: the Coronary Artery Risk Development in Young Adults (CARDIA) Study. Am J Epidemiol 163:929-937

14. Kataja-Tuomola M, Sundell JR, Mannisto S et al (2008) Effect of alpha-tocopherol and beta-carotene supplementation on the incidence of type 2 diabetes. Diabetologia 51:47-53

15. Reunanen A, Knekt P, Aaran RK, Aromaa A (1998) Serum antioxidants and risk of non-insulin dependent diabetes mellitus. Eur J Clin Nutr 52:89-93

16. Vatassery GT, Morley JE, Kuskowski MA (1983) Vitamin E in plasma and platelets of human diabetic patients and control subjects. Am J Clin Nutr 37:641-644

17. Liu S, Lee IM, Song Y et al (2006) Vitamin E and risk of type 2 diabetes in the women's health study randomized controlled trial. Diabetes 55:2856-2862

18. Liu S, Ajani U, Chae C, Hennekens C, Buring JE, Manson JE (1999) Long-term beta-carotene supplementation and risk of type 2 diabetes mellitus: a randomized controlled trial. JAMA 282: $1073-1075$

19. Byberg L, Zethelius B, McKeigue PM, Lithell HO (2001) Changes in physical activity are associated with changes in metabolic cardiovascular risk factors. Diabetologia 44:2134 2139

20. Matthews DR, Hosker JP, Rudenski AS, Naylor BA, Treacher DF, Turner RC (1985) Homeostasis model assessment: insulin resistance and beta-cell function from fasting plasma glucose and insulin concentrations in man. Diabetologia 28:412-419

21. Milne DB, Botnen J (1986) Retinol, alpha-tocopherol, lycopene, and alpha- and beta-carotene simultaneously determined in plasma by isocratic liquid chromatography. Clin Chem $32: 874-876$

22. Thurnham DI, Davies JA, Crump BJ, Situnayake RD, Davis M (1986) The use of different lipids to express serum tocopherol: lipid ratios for the measurement of vitamin E status. Ann Clin Biochem 23:514-520

23. Sundstrom J, Lind L, Nystrom N et al (2000) Left ventricular concentric remodeling rather than left ventricular hypertrophy is related to the insulin resistance syndrome in elderly men. Circulation 101:2595-2600

24. Zethelius B, Hales CN, Lithell HO, Berne C (2004) Insulin resistance, impaired early insulin response, and insulin propeptides as predictors of the development of type 2 diabetes: a population-based, 7-year follow-up study in 70-year-old men. Diabetes Care 27:1433-1438

25. Gopaul NK, Anggard EE, Mallet AI, Betteridge DJ, Wolff SP, Nourooz-Zadeh J (1995) Plasma 8-epi-PGF2 alpha levels are elevated in individuals with non-insulin dependent diabetes mellitus. FEBS Lett 368:225-229

26. Basu S, Helmersson J (2005) Factors regulating isoprostane formation in vivo. Antioxid Redox Signal 7:221-235

27. Riserus U, Basu S, Jovinge S, Fredrikson GN, Arnlov J, Vessby B (2002) Supplementation with conjugated linoleic acid causes 
isomer-dependent oxidative stress and elevated C-reactive protein: a potential link to fatty acid-induced insulin resistance. Circulation 106:1925-1929

28. Paolisso G, Giugliano D (1996) Oxidative stress and insulin action: is there a relationship? Diabetologia 39:357-363

29. Rudich A, Tirosh A, Potashnik R, Hemi R, Kanety H, Bashan N (1998) Prolonged oxidative stress impairs insulin-induced GLUT4 translocation in 3T3-L1 adipocytes. Diabetes 47:15621569

30. Davi G, Ciabattoni G, Consoli A et al (1999) In vivo formation of 8-iso-prostaglandin f2alpha and platelet activation in diabetes mellitus: effects of improved metabolic control and vitamin $\mathrm{E}$ supplementation. Circulation 99:224-229

31. Upritchard JE, Schuurman CR, Wiersma A et al (2003) Spread supplemented with moderate doses of vitamin $\mathrm{E}$ and carotenoids reduces lipid peroxidation in healthy, nonsmoking adults. Am J Clin Nutr 78:985-992

32. Schmidt MI, Duncan BB, Sharrett AR et al (1999) Markers of inflammation and prediction of diabetes mellitus in adults (Atherosclerosis Risk in Communities study): a cohort study. Lancet 353:1649-1652

33. Estrada DE, Ewart HS, Tsakiridis T et al (1996) Stimulation of glucose uptake by the natural coenzyme alpha-lipoic acid/thioctic acid: participation of elements of the insulin signaling pathway. Diabetes 45:1798-1804

34. Lopez-Ridaura R, Willett WC, Rimm EB et al (2004) Magnesium intake and risk of type 2 diabetes in men and women. Diabetes Care 27:134-140
35. Song Y, Manson JE, Buring JE, Sesso HD, Liu S (2005) Associations of dietary flavonoids with risk of type 2 diabetes, and markers of insulin resistance and systemic inflammation in women: a prospective study and cross-sectional analysis. J Am Coll Nutr 24:376-384

36. van Dam RM, Feskens EJ (2002) Coffee consumption and risk of type 2 diabetes mellitus. Lancet 360:1477-1478

37. Svilaas A, Sakhi AK, Andersen LF et al (2004) Intakes of antioxidants in coffee, wine, and vegetables are correlated with plasma carotenoids in humans. J Nutr 134:562-567

38. Valtuena S, Del Rio D, Pellegrini $N$ et al (2007) The total antioxidant capacity of the diet is an independent predictor of plasma beta-carotene. Eur J Clin Nutr 61:69-76

39. Roberts LJ 2nd, Oates JA, Linton MF et al (2007) The relationship between dose of vitamin $\mathrm{E}$ and suppression of oxidative stress in humans. Free Radic Biol Med 43:1388-1393

40. Ben-Amotz A, Levy Y (1996) Bioavailability of a natural isomer mixture compared with synthetic all-trans beta-carotene in human serum. Am J Clin Nutr 63:729-734

41. Brigelius-Flohe R, Traber MG (1999) Vitamin E: function and metabolism. FASEB J 13:1145-1155

42. Hoppe PP, Krennrich G (2000) Bioavailability and potency of natural-source and all-racemic alpha-tocopherol in the human: a dispute. Eur J Nutr 39:183-193

43. Comstock GW, Alberg AJ, Helzlsouer KJ (1993) Reported effects of long-term freezer storage on concentrations of retinol, betacarotene, and alpha-tocopherol in serum or plasma summarized. Clin Chem 39:1075-1078 